Article

\title{
A Study on Selecting Greenhouse Gas Reduction Options: A Simulation Analysis for Vietnam
}

\author{
Anh Quynh Tang ${ }^{1}$ (D) and Takeshi Mizunoya ${ }^{2, *(D)}$ \\ 1 Graduate School of Life and Environmental Sciences, University of Tsukuba, 1-1-1 Tennodai, \\ Tsukuba 305-8572, Ibaraki, Japan; tqanh.vn@gmail.com \\ 2 Faculty of Life and Environmental Sciences, University of Tsukuba, 1-1-1 Tennodai, Tsukuba 305-8572, \\ Ibaraki, Japan \\ * Correspondence: mizunoya.takeshi.ff@u.tsukuba.ac.jp
}

Citation: Tang, A.Q.; Mizunoya, T. A Study on Selecting Greenhouse Gas Reduction Options: A Simulation Analysis for Vietnam. Sustainability 2021, 13, 13530. https://doi.org/ $10.3390 /$ su132413530

Academic Editor: Mohammad Aslam Khan Khalil

Received: 18 October 2021

Accepted: 26 November 2021

Published: 7 December 2021

Publisher's Note: MDPI stays neutral with regard to jurisdictional claims in published maps and institutional affiliations.

Copyright: (C) 2021 by the authors. Licensee MDPI, Basel, Switzerland. This article is an open access article distributed under the terms and conditions of the Creative Commons Attribution (CC BY) license (https:/ / creativecommons.org/licenses/by/ $4.0 /)$.

\begin{abstract}
When it comes to greenhouse gas (GHG) mitigation, both bottom-up and top-down policies have limitations. Bottom-up policies are region-specific and cannot be applied at the national level. Top-down policies may not balance the considerations of economic growth and the environment. Therefore, a combined approach is necessary. This Vietnamese case study investigates optimal GHG mitigation options for both economic development and emission reduction by simulating four scenarios characterized by the different carbon tax and subsidy rates. Interventions, like replacing old buses with low-carbon buses and conventional electricity generation with solar power, are considered in a dynamic input-output framework. The objective function is Green GDP-industries' total value added reflecting GHG emissions' social cost. The simulation model comprises four cases: business as usual, low subsidy rate (up to $10 \%$ ), medium subsidy rate (up to $20 \%$ ), and high subsidy rate (up to $30 \%$ ), which are analyzed on parameters, including economic development, GHG emissions, and development of innovative sectors, like transportation and electricity. In three cases with different subsidy rates, the optimal carbon tax is simulated at the rate of USD $1 / \mathrm{tCO}_{2}$ equivalent, the lowest rate among the world's current carbon prices. In addition, the medium subsidy (up to $20 \%$ ) option yields the most competent scheme, with the highest GHG emission reduction and economic development effectiveness.
\end{abstract}

Keywords: carbon tax; green subsidy; greenhouse gas emissions; nonlinear programming; optimization; Vietnam

\section{Introduction}

Vietnam was the ninth most affected country by climate change in the two decades from 1998 to 2017 and ranked high on indexes such as expected climate change-related deaths and total losses [1]. Annually, tropical storms, typhoons, and flooding destroy thousands of houses, injure and kill people, destroy livelihoods, and damage infrastructure.

Vietnam's climate change risk differs by region. The Northern Mountain and Central areas have long confronted the risk of frequent and intense flash floods and landslides because of varying rainfall. According to the Central Committee for Flood and Storm Control, between 1990 and 2010, 74 floods led to severe consequences. For example, in 1997, there were 3000 people dead or missing, 100,000 collapsed houses, and more than 300,000 hectares of damaged crops after Typhoon Linda [2]. Concurrently, drought and water scarcity have exacerbated desertification, especially in the Central and South-Central Coast, Red River Delta, Midland, and Central Highlands regions [2]. Scorching, dry weather puts forest areas at a higher risk; from 1992 to 2013, Vietnam lost approximately 6000 hectares of forest per year due to forest fires [3].

In addition to loss and damage from unprecedented disasters, sea-level rise, a consequence of climate change, dramatically affects Vietnam's coastal communities. Climate 
change affects coastal communities by shrinking the agricultural cultivation land, aquaculture area, and saline land area. Sea level rise has shrunk agricultural cultivation land, aquaculture area, and residential land available to coastal residents. Suppose the sea level rises by $100 \mathrm{~cm}$ without effective response solutions; in that case, about $17.8 \%$ of Ho Chi Minh City and $38.9 \%$ of the Mekong River Delta will be at the risk of inundation, affecting a population of 21.49 million, which is about $10 \%$ to $12 \%$ of the country's population, erasing nearly $10 \%$ of its GDP [3].

In 1986, Vietnam launched Doi Moi, a political and economic reform that ended the centralized quota economy and initiated a market-based economy by intensifying private sector engagement [4]. Since then, Vietnam's economy has grown massively, transforming it from one of the poorest countries in the world to a middle-income country [5]. Vietnam's GNI per capita in 2016 surpassed the low-middle-income threshold at USD 2080 per capita [6]. A side effect of this rapid economic development was the dramatic rise in greenhouse gas (GHG) emissions, exacerbating Vietnam's vulnerability toward climate change.

Vietnam has actively contributed to prompt action on climate change in international forums. It signed the United Nations Framework Convention on Climate Change (UNFCCC) in 1992 [7], the Kyoto Protocol in 2002, and the Paris Agreement (PA) in 2016. This commitment is not only a challenge but also an opportunity for sustainable development. The PA emphasizes the leading role of developed countries in mobilizing climate change mitigation and adaptation in terms of financial support for developing countries [8].

The Third National Communication of Vietnam submitted to UNFCCC in 2019 outlines the obstacles to implementing its climate policies. As Vietnam is a developing country, budget allocation for high-priority issues seems to be a problem. In aiming for economic growth and climate response targets simultaneously, Vietnam needs more practical methods for decision makers to select optimal policy options. Each economic policy instruments affect the whole economy because of the interconnection between sectors. Therefore, it is necessary to project the impact of the proposed policy [9]. One such pragmatic approach is policy effectiveness evaluation to apportion expenditure efficiently.

That said, climate policies are insufficient and unstable without international financial support. Of the 45 mitigation options mentioned in Vietnam's Nationally Determined Contribution (NDC), which outlines the post-2020 climate actions countries intend to take under the new international agreement, $45 \%$ need international financial help [7]. This problem makes mitigation scenarios for Vietnam unsustainable in the long term and hinders internal advancement.

The solution could be introducing an additional carbon tax to supplement public expenditure for environmental protection and climate change response. Along with these tax policy changes, the government should prioritize tax administration reform [10]. This study investigates the allocation of tax revenue as a subsidy for innovative GHG reduction options. This self-sufficient tax and subsidy mechanism is considered in terms of impact on economic growth. Aiming for a sustainable economy, Vietnam's policymakers and scientists have analyzed several climate change mitigation options [3]. Each has to meet the requirements of extensive application capacity and inter-sectorial cover [11].

The good-practice mitigation policies for global replication are indicated in five major sectors with the corresponding share in global GHG emissions: electricity generation (25\%); industry and fossil fuel production (29\%); buildings (7\%); transport (13\%); fluorinated gases $(3 \%)$; land use, land use change, and forestry $(7 \%)$; and agriculture and waste $(15 \%)$ [12]. The two most competent mitigation sectors after the industry and fossil fuel production are electricity generation and transport. Moreover, another study for OECD member countries declares that the majority, over $70 \%$, of total GHG emissions come from power generation and transport [13]. The prevalent mitigation measures for the energy sector are superseding fuel to less carbon-intensive sources such as natural gas, promoting renewable energy technologies, and enhancing energy efficiency [13]. With the assessment of mitigation potential and investment cost, in the energy sector, Vietnam has set a priority 
for renewable energy generation and green transportation by promising a GHG reduction of 86.8 and 24.1 million tons $\mathrm{CO}_{2}$ equivalent [14].

GHG emission mitigation may be done through both top-down and bottom-up approaches. Bottom-up GHG mitigation encourages stakeholder participation in climate change response but cannot be applied nationally because of differing local conditions. Thus, bottom-up mitigation approaches must be assessed for feasibility and adaptability under varying local conditions. Climate-friendly agricultural cultivation designs are an example of bottom-up mitigation $[15,16]$. Innovative agricultural production concepts are analyzed to encourage local farmers' participation in climate change mitigation. Another bottom-up approach for GHG mitigation in the transportation sector is the decrement of emissions from idling vehicles by considering expressway upgradation. The abatement of traffic congestion has been found to reduce GHG emissions by decreasing travel time [17].

In contrast, a top-down approach can be applied widely to capture future macroscopic changes on a national scale. It is useful for policymakers to determine appropriate and feasible options for GHG mitigation. Top-down approaches can improve effectiveness with limited resources but have difficulty balancing economic growth and environmental protection. A top-down case study of Vietnam, in general, may not apply precisely for all areas and conditions in the country. For example, in the forestry sector, the OpCost model uses land-use changes' opportunity cost to evaluate different incentive rates for Reducing Emissions from Deforestation and forest Degradation (REDD+) activities [18]. The model's utility in determining the distribution of forest protection benefits for more sustainable forest reserves and local inhabitants' livelihoods is claimed to be applicable on a national scale to increase the policy's outcome [18]. However, the model's GHG mitigation effectiveness is ambiguous. Another case study of the top-down approach is the fuel tax to achieve GHG reduction goals in Bangladesh. The analysis utilizes the correlative model to estimate emissions reduction from fuel tax [19]. However, this economic model unintentionally ignores the self-correcting free market mechanism.

To summarize, each approach, whether bottom-up or top-down, has specific advantages and drawbacks that need to be considered in the policymaking process. Bottom-up approach proposes innovative schemes that can be applied on a more extensive scale [15], while top-down approach analyses the effectiveness of new regulations or the enforcement of technology transfer [19]. The best method for policymakers is combining the two to analyze both economy-wide and price-based policies with innovative technological policy options [20].

The utilization of innovative technologies is evaluated among the 45 mitigation options in the Technical Report of Vietnam's NDC. The report proposed innovative GHG mitigation options for four primary sectors: energy, agriculture, land use, land-use change and forestry (LULUCF), and waste. Among these, the energy sector's mitigation options have the most capacity and diverse options. Seventeen mitigation options have been proposed for the energy sector, with the potential to eliminate 45.78 million tons of $\mathrm{CO}_{2}$ equivalent [14]. According to the current national electricity database, Vietnam's electricity generation is unsustainable due to dependency on fossil fuels. Total electricity generation in Vietnam exceeded $130 \mathrm{TWh}$ in 2013, with an average growth rate ranging from 5 to $15 \%$ per year [21]. The primary sources of electricity generation in Vietnam are hydro, gas, oil, and coal. At the end of $2018,58.5 \%$ of power production was fully generated from fossil fuels [22].

Furthermore, GHG emissions from transportation represent the equivalent of 30.6 million tons $\mathrm{CO}_{2}$, or $10.8 \%$ of total GHG emissions in 2014 [3]. Therefore, Vietnam's NDC aims to promote public transport while fostering energy-efficient, low-carbon modes of transportation. The existing public transport system relies on diesel buses with low ridership levels and relatively high emissions. Typical buses even have slightly higher $\mathrm{CO}_{2}$ intensity per passenger-kilometer than motorcycles, which are the dominant mode of transport in Vietnam, accounting for $60 \%$ of total vehicle trips [23]. Under current circumstances, fostering public transport and achieving a mode shift would, therefore, increase GHG emissions. The NDC will reverse this situation by triggering a transformational shift from 
diesel-powered, high-emitting urban buses toward hybrid and electrified public transport. Only by 2025 will Vietnam acquire low-carbon buses (LCBs), defined as hybrid or electric buses for urban transit, in the Nationally Appropriate Mitigation Action (NAMA) scenario [24]. Existing bus operations will be improved through operational efficiency measures. Public transport planning and management will be enhanced by designing and establishing a national urban mobility policy and promoting actions to increase public transport's attractiveness [25].

LCB is a proven technology that has been mass deployed in many developed countries [26]. Hybrid buses are a mature technology and can be used on any route with bus availability rates comparable to diesel units, yielding proven fuel-savings of $25-35 \%$. Plugin hybrid buses save up to $40 \%$ fuel, thereby enabling reduced fossil fuel dependence and future electrification of the public transportation system through opportunity charging (en route charging stations), currently established in various cities worldwide. Many cities' experience, however, is that the successful deployment of hybrid buses requires a kick-start with a sizable fleet (more than 50 buses) to avoid high maintenance costs and low bus availability, which are problems typical of pilot-test fleets. The proposed investment scale for LCB is compiled from the NAMA Support Project (NSP) Low Carbon Bus Vietnam.

This study's primary purpose is to assess different environmental and technological intervention scenarios for Vietnam's NDC mitigation measures. The principal research question is how the simulation method and findings may be applied to support decisionmakers to evaluate different schemes aimed at NDC targets in Vietnam. Three specific objectives are set to address this question. The first is to assess the impact on economic growth and the effectiveness in reducing GHG emissions of different policy options. The proposed policy instrument is the environmental economic policy, including a carbon tax and subsidy to promote less emission-intensive industries. According to Vietnam's NDC report, each policy option constructed for GHG emission reduction reduces $8 \%$ of GHG emissions compared to the business as usual (BAU) scenario with domestic effort. The second objective is to indicate the criteria for policymakers to prioritize mitigation interventions. These criteria will help harmonize both the economic development target and the GHG emission reduction target. Vietnam is a developing country targeting ambitious economic growth. Hence, it needs an approach to optimize the mobility of limited resources for both economic and environmental targets. The third objective is to recommend an optimal GHG reduction option for the government. The optimal choice should be the option that meets the GHG reduction commitment while maximizing national economic growth. The proposed GHG reduction option is assessed in the context of the current legal framework.

This study focuses on simulation analysis to select the optimal GHG reduction options for Vietnam. In our simulation model, the options considered are converting from conventional to renewable energy generation and replacing old buses with low-carbon buses. Further, the novelty and significance of this study are emphasized as follows:

(1) Our input-output (IO) model is closer to a general equilibrium system than the conventional Leontief-type model. The model constructs an economy in which a commodity's quantity and price are determined simultaneously through the interdependent interaction of the commodity flow balance equation and the value flow balance equation.

(2) In our model, the material balance equation and value balance equation act interdependently. Therefore, the final demand, which is given exogenously in the conventional Leontief-type model, can instead be endogenously determined.

\section{Materials and Methods}

Policies have economy-wide effects that need to be quantified through modeling [27]. There are two main types of economic models: ex ante and ex post analysis. The ex ante analysis is used to assess the impact of the proposed policies in the future, given a baseline 
scenario. Meanwhile, the ex post analysis is utilized to review past policies' impact through historical data.

The two most common quantitative methods are IO analysis and computable general equilibrium (CGE) [28]. The characteristics of the two models are differentiated in Table 1. The most fundamental difference is that CGE describes an entire economy where all income earned is expended on different goods, whereas the conventional IO model is a partial economic analysis that does not link to income or consumption [28]. However, our model is structured such that income and consumption can be determined endogenously through the interdependent interaction of the material balance equation and the value balance equation. The CGE is more complicated, with nonlinear mathematics, but still has its weaknesses, which includes ignoring capital movement across nations and overestimating the trade effect [27]. The constant elasticity of CGE is believed to undermine the productivity function and proficiency in the international competitive market.

Table 1. Comparison of IO and CGE approaches to important modeling characteristics.

\begin{tabular}{ccc}
\hline Characteristics & IO & CGE \\
\hline Time horizon & Short run & $\begin{array}{c}\text { Short, medium, and long run } \\
\text { Nonlinear/advanced }\end{array}$ \\
Mathematical complexity & Linear/simple & General equilibrium \\
Model type & Partial economic analysis & (system) effects \\
& Accounted for via & Accounted for via \\
Sector interdependencies & technical coefficients & (cross)-elasticities \\
\hline
\end{tabular}
Source: [28].

Therefore, IO analysis is chosen for this study because of the simplicity of the mathematical approach.

Moreover, IO analysis has an advantage over CGE in that it can analyze in detail changes in output and GHG emissions in each sector due to policy spillovers. IO analysis is based on a technical coefficient matrix, which is politically neutral; that is, IO analysis is applicable for capitalist, socialist, or traditional Third World economies [29]. Meanwhile, CGE utilizes a fixed elasticity of substitution among exports in different industries, which implies manipulating the trading system [27]. The IO analysis in this study uses a time series for the proposed policies' projected impact. The IO model's environmental extension can be applied to assess the relationship between economic growth and environmental pollution [29]. The optimization IO model results are the best scenario(s) of policies that could harmonize economic development and environmental protection targets.

IO analysis is first used to analyze the interdependence of one industry's (sector's) sales with another sector [30]. This methodology has been applied to various economic problems [31] and has been extended to set forth many new extensions that can be used to integrate additional details of economic activities [32]. Since the late 1960s, studies have extended IO analysis to environmental pollution formation [32] and environmental pressures across the economy [33].

Economic policies are the most common subject of the extended IO analysis in environmental economics. Here, we consider tax and subsidy mechanisms to adjust emissionintensive industries' production. IO analysis is used to assess the policy impact on both economic and environmental aspects to evaluate productivity changes and abatement activities [34]. The increasing environmental tax enhances the efficiency of environmental exploitation and reduces emission-intensive activities [34].

\subsection{Introduction of the Simulation Model}

This study utilizes dynamic IO analysis with three main modules-the Socioeconomic Model, GHG Emissions Flow Model, and Investment and Saving Model, as shown in Figure 1. The baseline data are constructed from the 2012 IO table of Vietnam, reflecting 
the relationship between the production process and externalities [35]. The model assumes three main stakeholders: government, households, and industries (as shown in Figure 2).

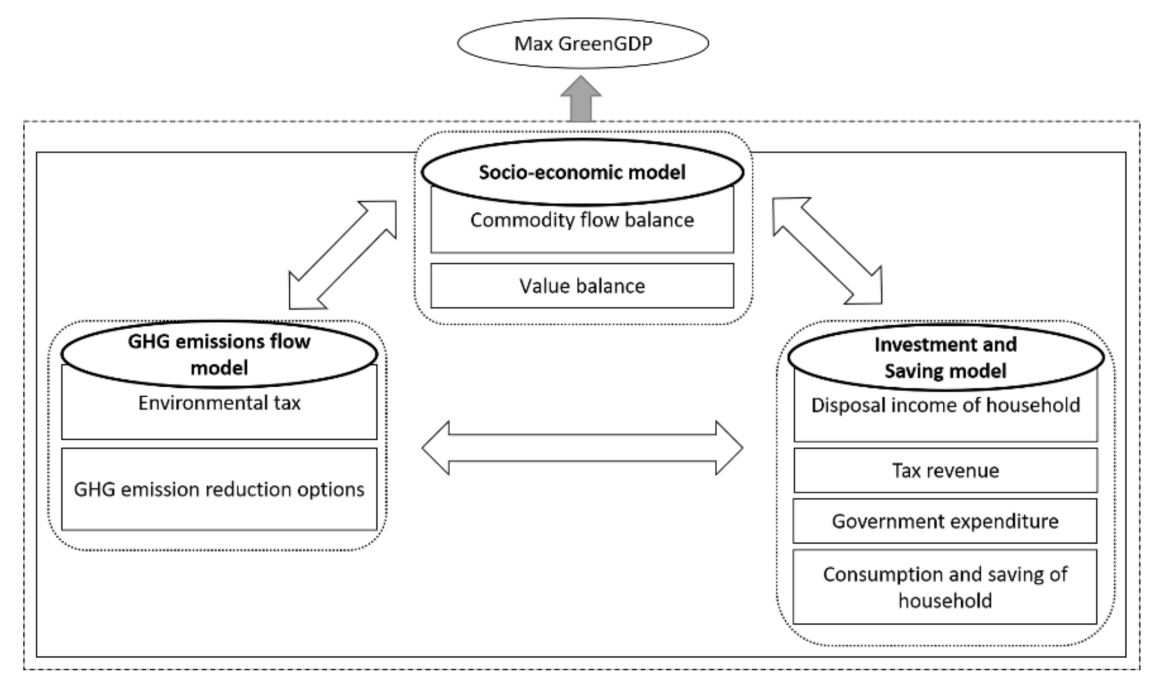

Figure 1. Model framework.

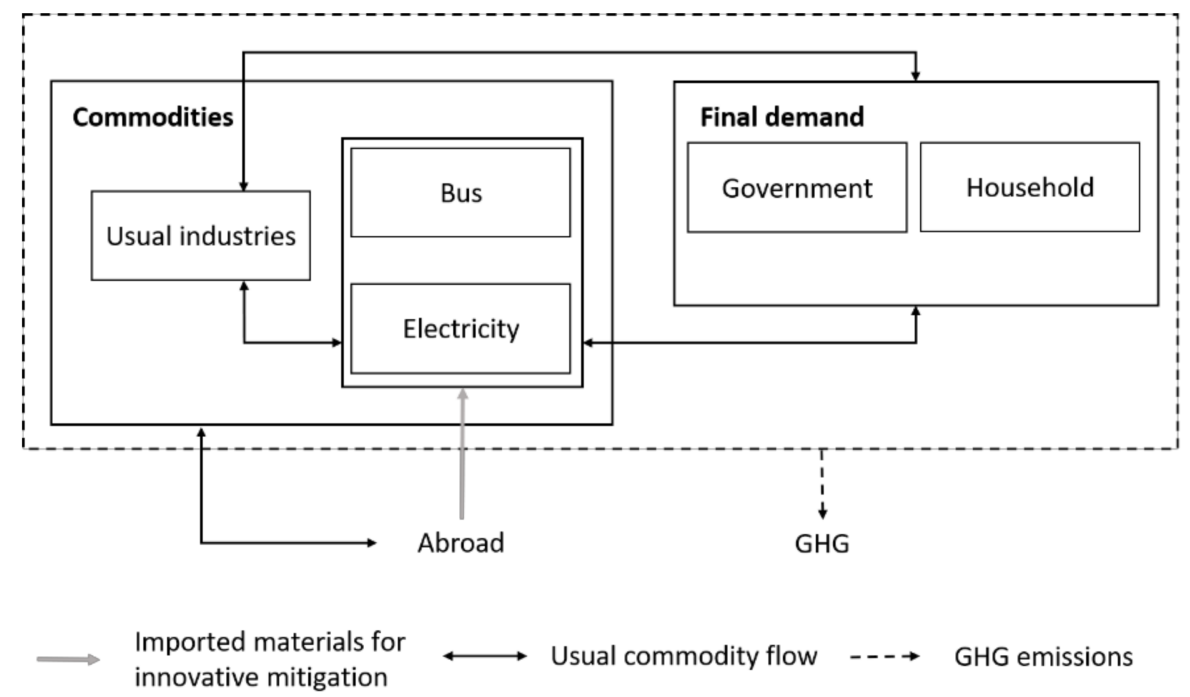

Figure 2. Interrelation in commodity flow.

The three innovative technologies considered in the model are low-carbon bus, wind, and solar energy generation, as mentioned in the Introduction section. The model assesses the effects of introducing low-carbon buses and renewable energy generation, partly substituted for the conventional transportation and energy sector. The promotion expenditure for these innovative technologies includes installation cost, operation cost, and maintenance cost. The investment matrix of each technology is described in Tables 2 and 3. 
Table 2. Investment matrix for wind and solar energy generation.

\begin{tabular}{ccccc}
\hline No. & Investment Cost & $\begin{array}{c}\text { Installation Cost } \\
\text { (mil. USD/MWac }\end{array}$ & $\begin{array}{c}\text { Fixed O\&M ** Cost } \\
\text { (USD/MWac */year) }\end{array}$ & $\begin{array}{c}\text { Variable O\&M Cost } \\
\text { (USD/MWh/year) }\end{array}$ \\
\hline 1 & $\begin{array}{c}\text { Onshore } \\
\text { wind power }\end{array}$ & 1.6 & 40.5 & 4.2 \\
\hline 2 & $\begin{array}{c}\text { Solar power } \\
\text { (sufficient for } \\
\text { power line) }\end{array}$ & 1.1 & 11 & 0 \\
\hline
\end{tabular}

${ }^{*}$ MWac stands for mega Watt alternative current. It is a measure of the power output from a solar installation after the output of the PV panels have been converted to AC via inverter devices. ** O\&M cost stands for operation and maintenance cost. Source: Adapted from [36].

Table 3. Investment cost of buses per unit.

\begin{tabular}{ccccc}
\hline (In USD) & Diesel & Hybrid & Plug-in Hybrid & Electric \\
\hline Investment & 120,000 & 162,000 & 192,000 & 928,571 \\
\hline Annual energy cost & 20,800 & 15,600 & 13,323 & 6400 \\
\hline $\begin{array}{c}\text { Annualized cost including } \\
\text { battery replacement }\end{array}$ & 36,900 & 38,633 & 41,307 & 145,148 \\
\hline Net present value relative to diesel & - & -9723 & $-27,380$ & $-703,624$ \\
\hline Surplus cost annualized per km & - & 0.022 & 0.055 & 1353 \\
\hline Total annual investment & 177,700 & 206,510 & 219,250 & 377,848 \\
\hline Source: Adapted from [24]. & & & &
\end{tabular}

\subsection{Design of the Model}

Each equation describes two types of variables in the simulation model: exogenous (ex) and endogenous (en). The exogenous variables take the base year as 2012, and the endogenous variables are generated from the simulation model. The simulation model is developed to cover a period of 18 years, from 2012 to 2030.

\subsubsection{Data Source}

The input-output table is the central database for this study. In Vietnam, the inputoutput table is conducted from national scale surveys once every five years. At the moment, Vietnam has published five input-output tables for 1989, 1996, 2000, 2007, and 2012. This research uses the last input-output table in 2012. The second important database for this research is GHG emissions matrix which is aggregated from 99 inventory sectors according to the GHG inventory report 2014 of the Ministry of Natural Resources and Environment. One hundred and sixty-four commodities in the IO table for Vietnam in 2012 are aggregated into 22 industries (see Table 4) and synchronized with the 99 sectors of the GHG inventory of Vietnam; this aggregation helps us conduct a comprehensive economic-environmental analysis. In addition to the raw data, we used $[14,24,25,36-39]$ to calculate the exogenous variables that need to be input to the model. 
Table 4. Industry classification.

\begin{tabular}{ll}
\hline No. & Industry \\
\hline 1 & Agriculture \\
\hline 2 & Mining \\
\hline 3 & Food products \\
\hline 4 & Textiles and clothing \\
\hline 5 & Paper and wooden products \\
\hline 7 & Chemical products \\
\hline 8 & Coal and petroleum products \\
\hline 9 & Non-metallic mineral products \\
\hline 10 & Iron and steel \\
\hline 11 & Non-ferrous metals \\
\hline 12 & Fabricated metal products \\
\hline 13 & Other manufactures \\
\hline 14 & Building and construction \\
\hline 15 & Gas \\
\hline 16 & Transport except for the bus \\
\hline 17 & Non-energy sectors \\
\hline 21 & Services \\
\hline 19 & Real estate services \\
\hline 22 & Other public services \\
\hline 10 Others \\
\hline 10
\end{tabular}

\subsubsection{Objective Function}

This model's objective function is to maximize the discounted Green GDP from 2012 to 2030 with all GHG emissions and supply-demand relations constraints. The GHG reduction options are introducing innovative sub-sectors, including low-carbon buses, solar energy generation, and wind energy generation. Owing to Vietnam's limited manufacturing ability and import tax exemption for renewable energy equipment [40], materials for low-carbon bus, solar, and wind energy generation are imported fully or partly from abroad. Therefore, the new sub-sector's investment is the sum of installation, operation, and maintenance costs. The outputs for bus and electricity are the sum of the conventional bus sector production, traditional electricity sector, and innovative sub-sectors.

$$
\text { Objective function }=\operatorname{Max} \sum_{t=1}^{18}\left(\frac{1}{1+\rho}\right)^{t-1} \text { Green } \operatorname{GDP}(t)
$$

$$
\begin{aligned}
\text { Green } \operatorname{GDP}(t)= & G D P(t)-\text { Depreciation of products }(t)-\text { Total social cost }(t) \\
& =v X_{i}(t)-\sum \operatorname{dep}_{i} \times X_{i}(t)-\sum Z_{i}(t) \times S C_{i}
\end{aligned}
$$

where $\operatorname{GDP}(t)$ is the gross domestic product in term $t(\mathrm{en}), X_{i}(t)$ is the production of each industry $i$ in term $t$ (en), and $\rho$ is the social discount rate (ex). The subscript $i$ is on the range of 22 industries that are aggregated, as mentioned above. 


\subsubsection{Commodity Flow Balance}

The construction of the commodity flow balance is based on the principle, "All expenditures from the demand side will be equal to or less than all expenditures from the supply side." [16,32]. The equation's right-hand side demonstrates all expenditures from the demand side, including intermediate consumption calculated by technical coefficient matrix, final consumption from household and government, investment of usual industries and bus, energy industries, and net export. The supply side, which is the output of industries, needs to meet the demand each year.

$$
\sum_{i=1}^{20} A_{i j} X_{i}(t)+C_{i}^{h}(t)+C_{i}^{g}(t)+I_{i}(t)+I_{e-\text { conv }}(t)+I_{e-\text { solar }}(t)+I_{e-\text { wind }}(t)+I_{\text {bus-conv }}(t)+I_{L C B}(t)+E_{i}(t)-M_{i}(t) \leq X_{i}(t)
$$

where $A_{i j}$ is an input coefficient matrix from industry $i$ to industry $j$ among the usual sectors except for the energy and bus industries (ex, matrix), $X_{i}(t)$ is the commodities of all sectors in industry $i$ (usual industries) in term $t$ (en, column vector), $C_{i}^{h}(t)$ is the household consumption amount of each sector in industry $i$ in term $t$ (en, column vector), $C_{i}^{g}(t)$ is the government consumption amount for each sector in industry $i$ in term $t$ (en, column vector), and $I_{i}(t)$ is the investment amount from each sector in industry $i$ in term $t$ (en, column vector). Further, $I_{e-c o n v}(t)$ is the investment demand for the conventional energy sector in term $t$ (en), $I_{e-\text { solar }}(t)$ is the investment demand for the solar energy sector in term $t(\mathrm{en}), I_{e-\text { wind }}(t)$ is the investment demand for the wind energy sector in term $t(\mathrm{en}), I_{b u s}(t)$ is the investment demand for the conventional bus sector in term $t(\mathrm{en}), I_{L C B}(t)$ is the investment demand for the low carbon bus sector in term $t$ (en), $E_{i}(t)$ is the export amount of each sector in industry $i$ in term $t$ (en, column vector), and $M_{i}(t)$ is the commodity import amount of each sector in industry $i$ in term $t$ (en, column vector).

\subsubsection{Value Flow Balance}

The value flow balance is built based on the principle that "total output must be equal to or more than total outlays." In other words, each industry only maintains its production if the total output generates enough revenues to exceed all expenditures. Price variation is expected in the market; therefore, this balance reflects the price matrix.

$$
P_{i}(t) A_{i j} X_{i}(t)+\tau A P_{m}^{i} X_{i}(t)+v X_{i}(t)+\tau \times A P_{m}^{f}\left[C_{i}^{h}(t)+C_{i}^{g}(t)\right] \geq P_{i}(t) X_{i}(t)
$$

where $P_{i}(t)$ is the price rate vector of each sector in industry $i$ in term $t$ (en, row vector), $\tau$ is emissions tax of industries (en, row vector), $v$ is the value-added rate of industries (ex, row vector), $A P_{m}^{i}$ is the coefficient of GHG $m$ emitted by industries (ex), and $A P_{m}^{f}$ is the coefficient of GHG $m$ emitted by final consumption (ex).

\subsubsection{GHG Emissions Constraint}

According to Vietnam's NDC, the restriction of GHG emissions means meeting the emissions target by 2030, which is reduced by $8 \%$ compared with BAU according to the NDC of Vietnam, which is 474.1 million tons $\mathrm{CO}_{2}$ equivalent by 2020 and 787.4 million tons $\mathrm{CO}_{2}$ equivalent by 2030 [7].

\subsection{Scenario Design}

The model analyzes four scenarios (Table 5) in the period from 2012 to 2020. Scenario 0 is the Baseline scenario with the optimization of Green GDP and no emissions constraint. Scenario 0 is built based on the 2012 technical coefficient matrix and GDP growth rate of $6 \%$ per year, the average GDP growth rate from 2012 to 2018 [6]. 
Table 5. Scenario design.

\begin{tabular}{cccc}
\hline Scenario & Emission Reduction & Emission Tax & Subsidy \\
\hline 0 & - & - & - \\
\hline 1 & $8 \%$ & + & Low (5-10\%) \\
\hline 2 & $8 \%$ & + & Medium (5-20\%) \\
\hline 3 & $8 \%$ & + & High (5-30\%) \\
\hline
\end{tabular}

Scenarios 1 to 3 simulate the optimal objective function with an emission reduction target of $8 \%$ compared with Baseline (Scenario 0 ), with the endogenous emission tax rate and subsidy rate for mitigation options. The emission tax rate varies between USD 1 and USD 131 per ton of $\mathrm{CO}_{2}$ equivalent, which is limited within existing carbon tax levels in the world [41]. The subsidy rate differs across three scenarios-low, medium, and high. The low subsidy rate ranges from 5 to $10 \%$; the medium varies from 5 to $20 \%$; the high varies from 5 to $30 \%$. The subsidy rate is based on the Law of Assistance for small- and medium-sized enterprises in 2017; government investment does not exceed $30 \%$ of the total investment [42]. The subsidy rate is defined to ensure financial support and avoid overdependence of industry entities simultaneously.

The simulation results can support the verification of the tax-subsidy policy. The cases provide insight into its impacts on economic growth and the reduction in GHG emissions. The quantitative assessment helps decision makers select optimal GHG reduction options that balance economic growth targets and climate change response commitments.

According to Vietnam's NDC report, the economic instrument is the most powerful tool to regulate emissions by targeting GHG reduction. The introduction of the self-sufficient tax/subsidy mechanism for Vietnam contributes to sustaining economic development and ensuring the GHG emission commitment. In this model, the tax rate varies from USD 1 to USD 131, which is the range of existing tax pricing across the world [41].

The three cases are built with three different levels of subsidies to promote innovative technological sub-sectors. The main target of the model is to select the optimal tax/subsidy in each scenario. The objective function is to maximize the sum of discounted Green GDP from 2012 to 2030.

\section{Results and Discussion}

\subsection{The Best Tax/Subsidy Scheme}

As shown in Figure 3, the objective function, for the subsidy rate of $20 \%$ per option, is the largest. Thus, the optimal tax and subsidy scheme is described in Case 3 . The specific optimal tax/subsidy rate in the three cases is demonstrated in Table 6.

In all three cases, the optimal carbon tax is simulated at the rate of USD $1 / \mathrm{tCO}_{2}$ equivalent, which is the lowest rate among the world's current carbon prices, varying between USD 1 and USD 131 [41]. The rate USD $1 / \mathrm{tCO}_{2}$ equivalent has been applied in Pilot ETS in Guangdong, Shanghai, and Chongqing, China; Mexico; and Poland as a carbon tax [41]. The rate of this carbon tax scheme for Vietnam is comparative with upper-middle-income countries, including China and Mexico. This optimal carbon tax rate is judicious because Vietnam is still trying to attain its economic ambitions and enhance its prestige and position in the international arena. Moreover, compared with current environmental economic instruments implemented in Vietnam, such as environmental taxes and fees, the rate of USD $1 / \mathrm{tCO}_{2}$ equivalent is realistic. The current environmental tax for fossil fuel is about USD 0.17 per liter of petrol, oil, and grease, converted to about USD $0.063 / \mathrm{tCO}_{2}$ equivalent [43]. In addition, another study on tax for fossil fuels proposes an increased $50 \%$ for coal and $33.3 \%$ for petroleum, which are about USD 2.5/ton $\mathrm{CO}_{2}$ equivalent and USD $0.084 /$ ton $\mathrm{CO}_{2}$ equivalent $[9,44,45]$. On the other hand, the research on phasing in the carbon tax and phasing out fossil fuel subsidies analyzes the simulation effect on macroeconomics. The proposed carbon tax rate for USD $12 /$ ton $\mathrm{CO}_{2}$ equivalent 
for intermediate and final consumption of coal, refined fuel, and natural gas from [46]. In summary, among the proposed carbon tax scheme for Vietnam, the proposed carbon tax of this study covers the whole emitted industries extensively with acceptable rate. Therefore, the proposed combined-tax-and-subsidy scheme is superior compared to other comparable studies for Vietnam.

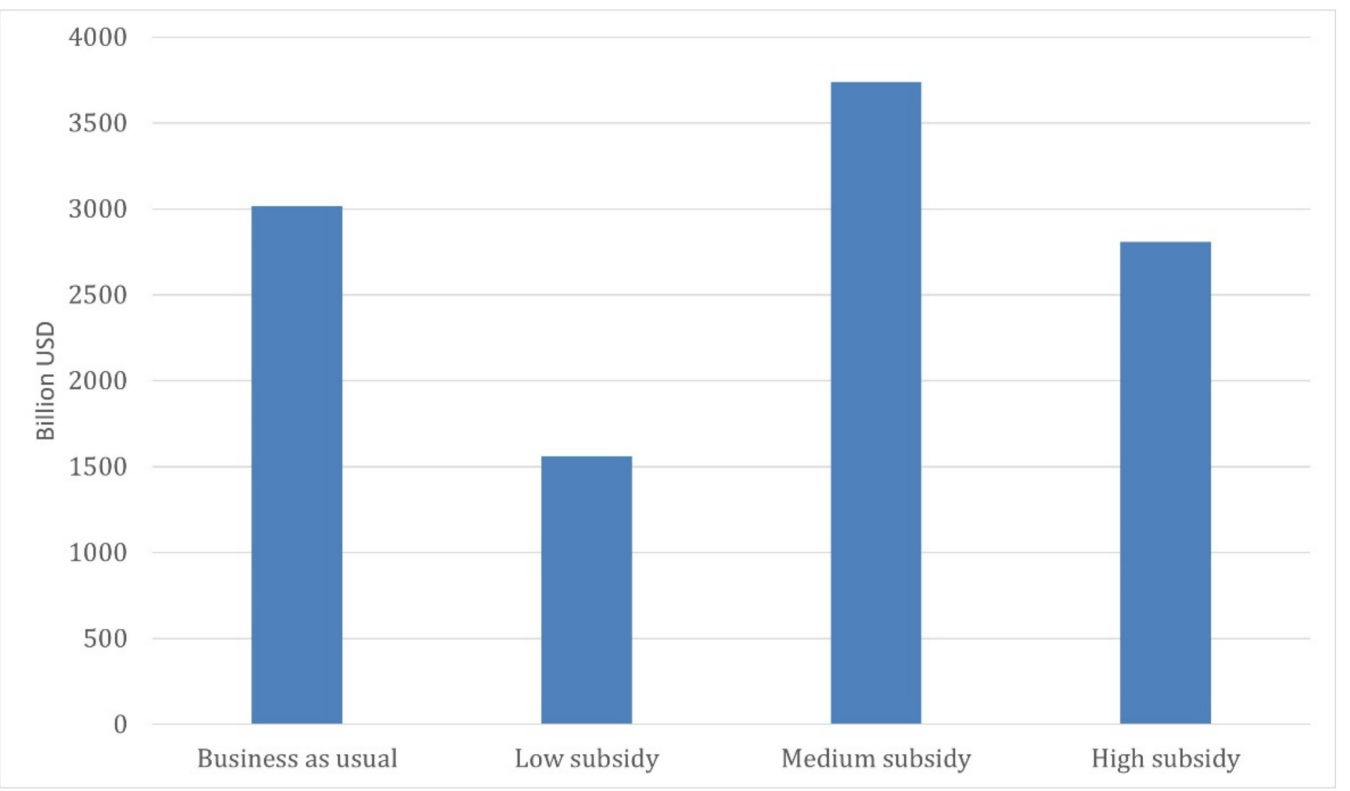

Figure 3. The objective function of different scenarios.

Table 6. The best tax/subsidy scheme in three scenarios.

\begin{tabular}{ccccc}
\hline Scenario & $\begin{array}{c}\text { Optimal Carbon Tax } \\
\text { (USD/tCO } \\
\text { Equivalent) }\end{array}$ & $\begin{array}{c}\text { Subsidy Rate for } \\
\text { Low-Carbon Bus (\%) }\end{array}$ & $\begin{array}{c}\text { Subsidy Rate for } \\
\text { Solar Energy (\%) }\end{array}$ & $\begin{array}{c}\text { Subsidy Rate for } \\
\text { wind Energy (\%) }\end{array}$ \\
\hline 1 & 1 & 10 & 10 & 10 \\
\hline 2 & 1 & 20 & 20 & 20 \\
\hline 3 & 1 & 5 & 30 & 30 \\
\hline
\end{tabular}

\subsection{Economic Development Trend}

Figure 4a shows the impact of the tax and subsidy scheme with different rates on economic development. The GDP of two cases, with low and high subsidy rates, is less than in the BAU scenario (Case 0). This deficit implies that the carbon tax plays a vital role in controlling all industries' production with the value balance relation. A tax scheme is asserted to create a new position of equilibrium through adjusted prices [47]. The taxed commodity's price will increase as the outlay exceeds the production cost by the amount of tax. Nevertheless, while all sectors' emission coefficient matrices are unchanged, imposing an additional tax hinders economic development. Therefore, the subsidy mechanism is proposed in coordination with tax policy to foster cleaner production. 


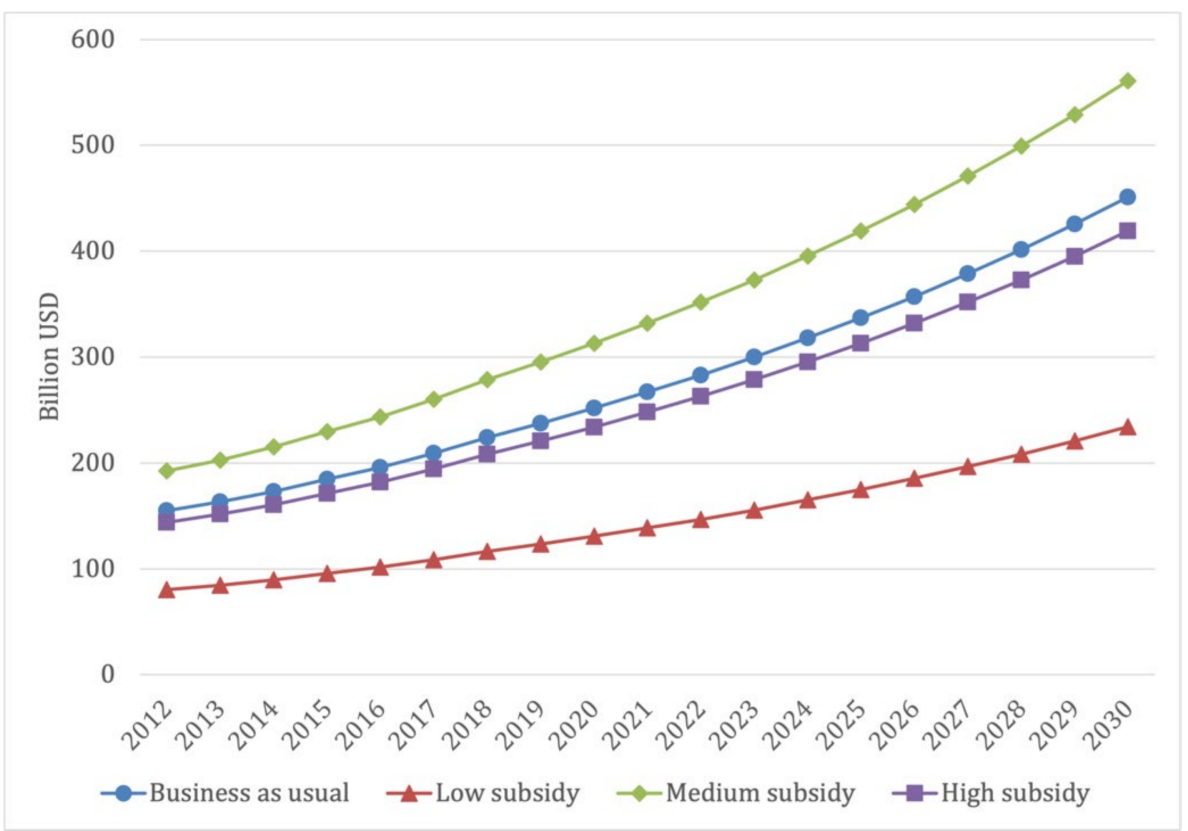

(a)

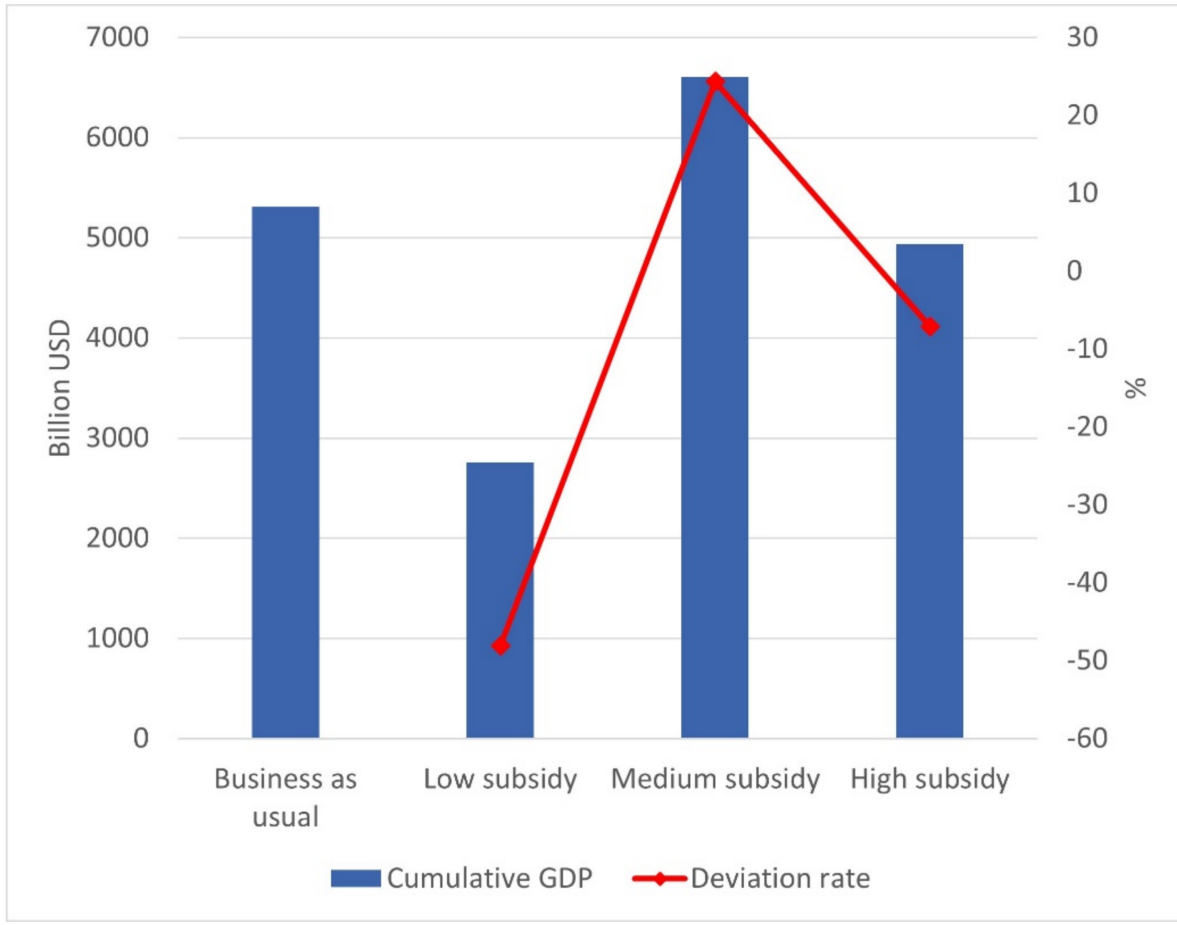

(b)

Figure 4. Economic development in different scenarios. (a) Economic development trend in different scenarios. (b) Cumulative GDP from 2012 to 2030 in different scenarios.

Figure $4 \mathrm{~b}$ also illustrates the total GDP in 18 years for four cases, with the deviation rate of cases compared with the BAU scenario (Case 0). Only with the medium-subsidy scenario does the cumulative GDP exceed the BAU scenario at $24 \%$. The cumulative GDP of low- and high-subsidy scenarios differs between $-48 \%$ and $-7 \%$ compared with the baseline. This negative development implies that the highest subsidy is not necessarily the optimal scenario for economic growth, perhaps because it requires a higher government budget expenditure and shrinks investment for all industries. The positive outcome of the 
medium-subsidy scenario may occur since appropriate subsidy promotes less emissionintensive sectors while applying the GHG emissions constraint among other sectors.

The simulative economic development of the medium-subsidy scenario denotes the positive effectiveness of the combine-tax-and-subsidy policy. This result is more competent compared with the solely increased tax for coal and petroleum scheme. The rising tax rate for coal and petroleum is forecasted to lessen the national GDP by $1.05 \%$ and $2.23 \%$, respectively, compared with baseline [9]. In addition, the forecasted expansion of GDP of the phasing out subsidy for fossil fuels and phasing in the carbon tax is $0.16 \%$ per year, which is a $2.24 \%$ aggregated increment compared with the base scenario [46]. Overall, the result of this study on combined-tax-and-subsidy policy is more remarkable than similar research on tax policy for Vietnam.

\subsection{Development of Innovative Sectors}

As discussed above, carbon tax plays a vital role in rectifying the development of emission-intensive industries. It is proposed that the tax revenue be used to allocate the subsidy for GHG reduction options, including replacing old buses with LCBs, solar energy generation, and wind energy generation. Therefore, the bus and energy industry's development is a prerequisite to the policy.

As seen in Figure 5a, the total bus industry production is deficient compared to the BAU scenario in low and high subsidy cases. In contrast, the most potential augmentation occurs in Case 2, with the same tax rate and medium subsidy range for all GHG reduction sub-sectors. The bus output in Case 2 exceeds $31 \%$ compared to Case 0 , even without the tax barrier.

The energy industry follows the same pattern, with the most competent development in the medium-subsidy scenario at $125 \%$ compared with Case 0 (Figure 5a). The carbon tax alone may curb the industry development because of the additional value added to the product. The increment of the price of taxed commodities contributes to the abatement in the intensive emission sectors. However, to optimize the competition of innovative production, the subsidy is apportioned to reduce the price of cleaner production.

After introducing cleaner production, the production of innovative sub-sectors in individual cases is allotted to the conventional sub-sector. The conventional bus sub-sector ratios of Cases 1, 2, and 3 decrease with individual rates of $62 \%, 13 \%$, and $71 \%$, respectively (Figure $5 b$ ). Similarly, the conventional energy ratio is shrinking, with respective $65 \%, 42 \%$, and $40 \%$ rates in cases 1,2 , and 3 (Figure $5 \mathrm{c}$ ). The wind and solar power production rates are expected to climb up to $2.7 \%$ by 2030 and $6 \%$ by 2030 , respectively [48]. Therefore, the simulation scenarios meet the government's ambition for renewable energy generation. The transition from an emission-intensive sector to a less discharge-heavy sector has a constructive effect on economic development and environmental protection.

Figure 6 demonstrates GHG emissions from the bus and energy industries between cases. For buses, emissions drop by $60 \%$ and $34 \%$ in Cases 1 and 3, respectively, and increase by $23 \%$ in Case 2 compared with Case 0 . The GHG emissions from the energy industry plunges by $81 \%, 28 \%$, and $43 \%$ in Cases 1,2, and 3, respectively, compared with Case 0 . This mitigation from these two industries contributes to loosening GHG emissions restrictions for the rest of the economy. 


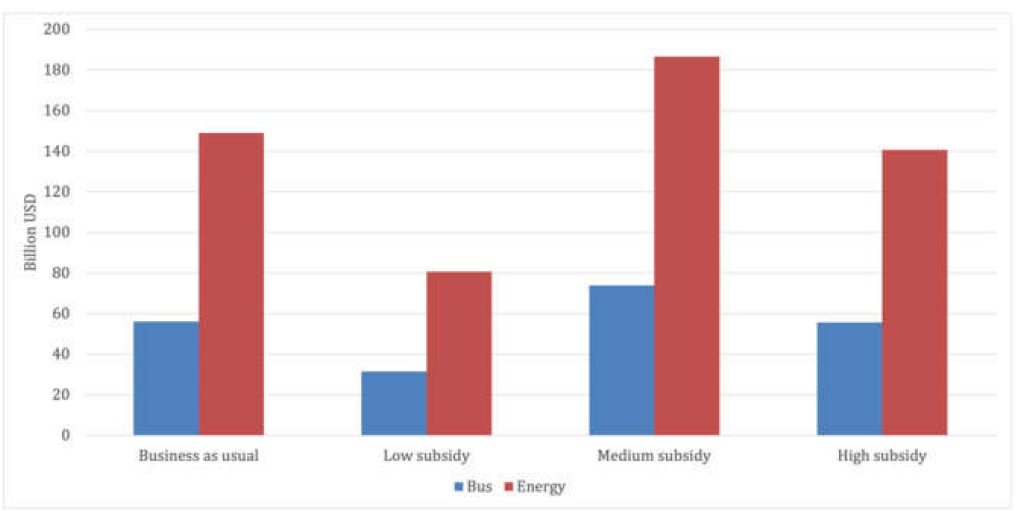

(a)

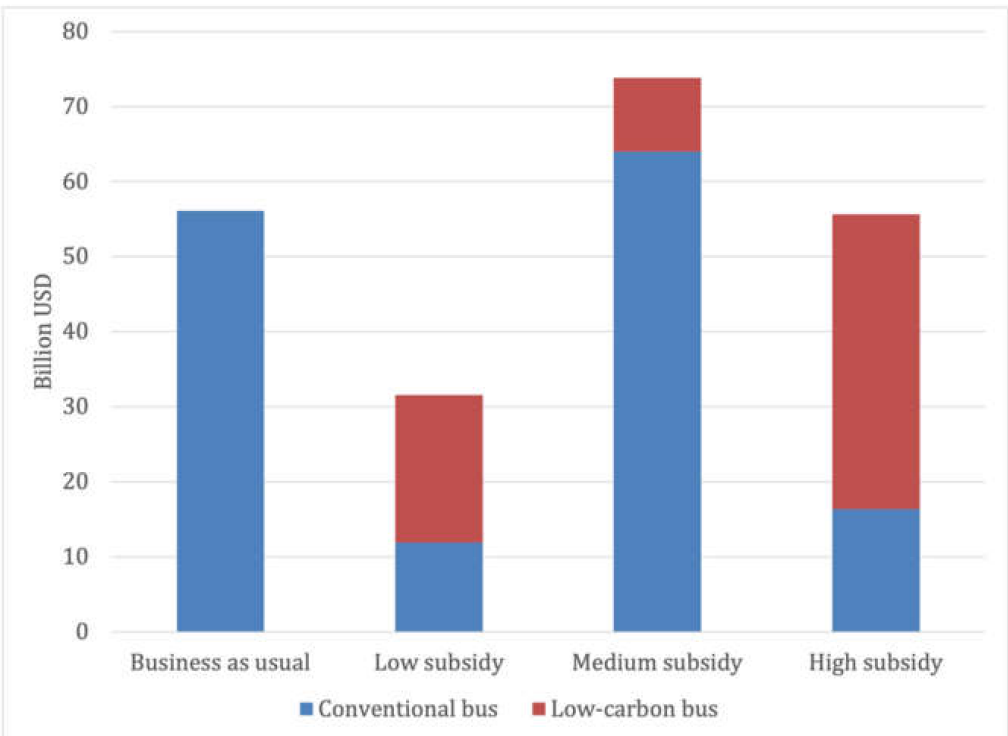

(b)

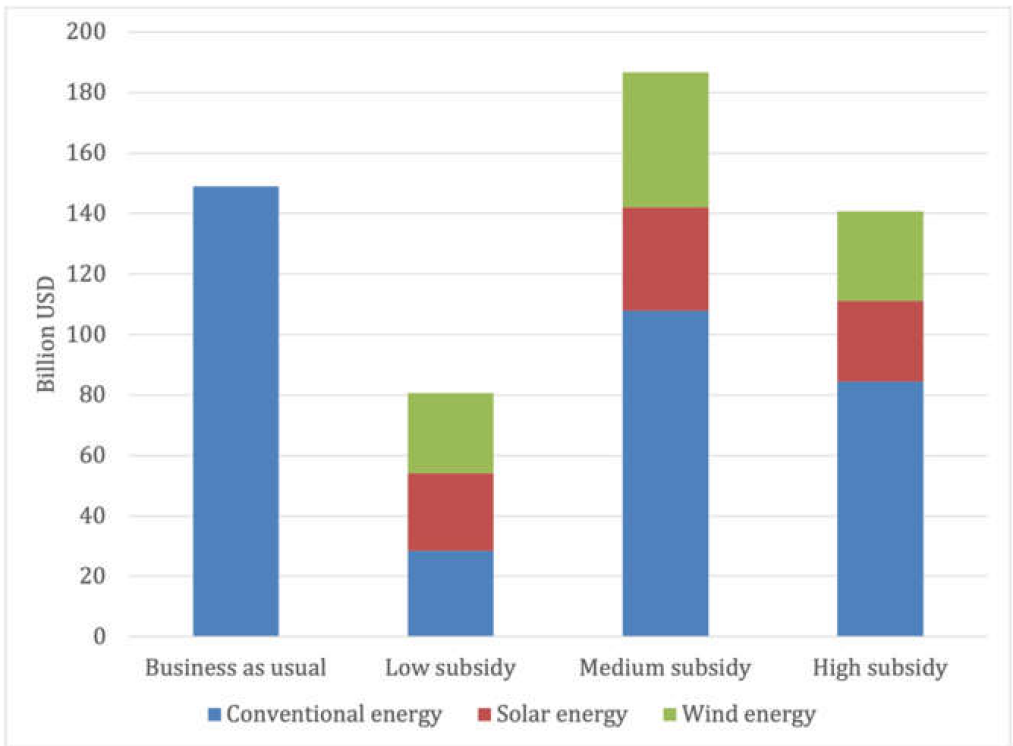

(c)

Figure 5. The development of innovative sectors. (a) The production of the bus and energy industries in different scenarios. (b) The development of the bus industry in different scenarios. (c) The development of the energy industry in different scenarios. 


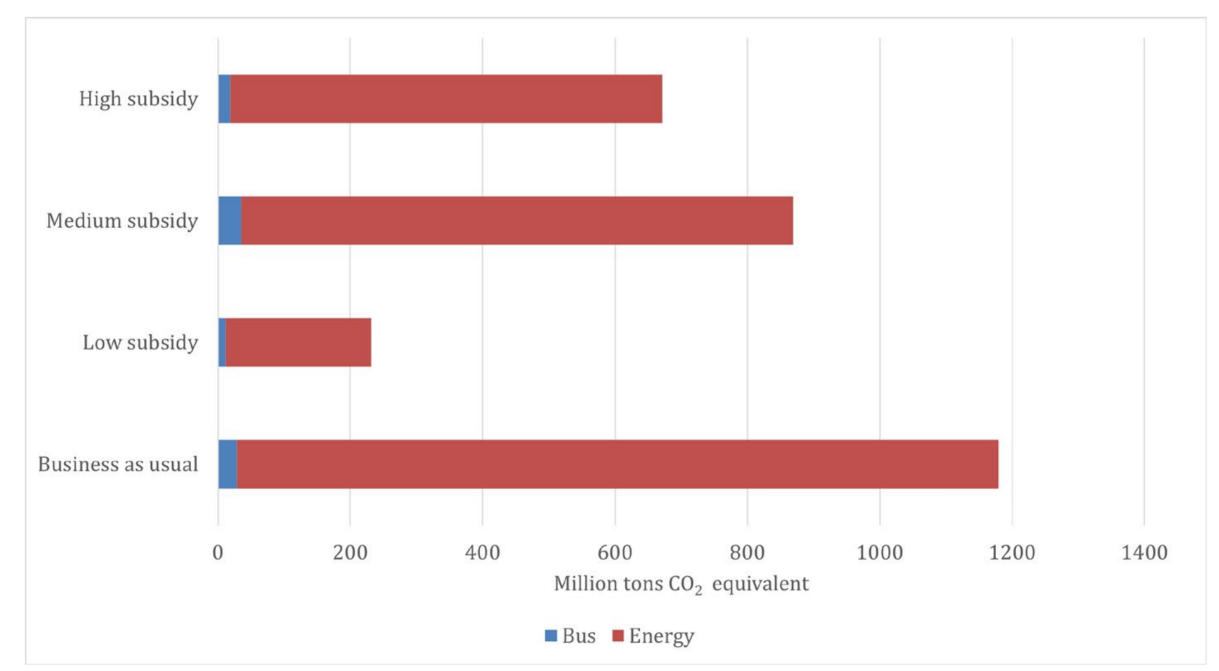

Figure 6. Comparison of GHG emission of the bus and energy industries between cases.

\subsection{GHG Emission Reduction and Emission Intensity Trend}

GHG emissions intensify along with economic development in the BAU scenario, up to 617.1 million tons $\mathrm{CO}_{2}$ equivalent by 2030. Figure 7a shows that GHG emissions in 2030 increase to $222.6 \%$ compared with the baseline year 2012 without tax and subsidy policy. GHG emissions, in 2030, with the proposed tax and subsidy policy, rise to 318.3, 724.4, and 574.6 million tons $\mathrm{CO}_{2}$ equivalent to a rate of $271 \%, 294 \%$, and $228 \%$ in Cases 1,2, and 3, respectively.

GHG intensity describes the relationship between economic development and GHG emissions, calculated by the emission amount per unit of the study area's GDP [49]. It validates the macro effect of the economic and environmental instruments, such as tax and subsidy. Figure $7 \mathrm{~b}$ shows that the combined carbon tax and subsidy contribute to lessening GHG intensity in all the three cases. Among the three cases, the average GHG intensity differs from 7 to $9 \%$ compared with the BAU scenario (Case 0 ). The average GHG intensity is 1277,1278 , and $1300 \mathrm{kt} \mathrm{CO}_{2}$ equivalent/billion USD with an alteration rate of $8.6 \%, 8.6 \%$, and $7 \%$ in Cases 1, 2, and 3, respectively (Figure $7 \mathrm{~b}$ ). The downward trend also signifies that global $\mathrm{CO}_{2}$ intensity has been firmly declining since 1990 [50]. Moreover, improvement in the GHG emission situation is likely to occur due to renewable energy capacity innovation. Figure 7a shows that all three scenarios meet the targeted GHG emissions mentioned in Vietnam's NDC, which is 474.1 million tons $\mathrm{CO}_{2}$ equivalent by 2020 and 787.4 million tons $\mathrm{CO}_{2}$ equivalent by 2030 [7]. However, only a medium-subsidy scenario exceeds the BAU's cumulative GHG emissions, with a rate of $116.4 \%$ (shown in Figures $7 \mathrm{a}$ and 8). Figure $9 \mathrm{a}-\mathrm{c}$ shows that, without any restriction of emissions, air pollution will rise steeply. In the baseline scenario, $\mathrm{CO}_{2}, \mathrm{CH}_{4}$, and $\mathrm{N}_{2} \mathrm{O}$ emissions will increase by $1.97,2.8$, and 1.87 times, respectively, compared with the level for 2012. In addition, the anticipation for GHG emissions and the government's economic development seem superior to the actual outcome. The projection for the total GHG emissions by 2030 is 787.4 million tons $\mathrm{CO}_{2}$ equivalent [7]. 


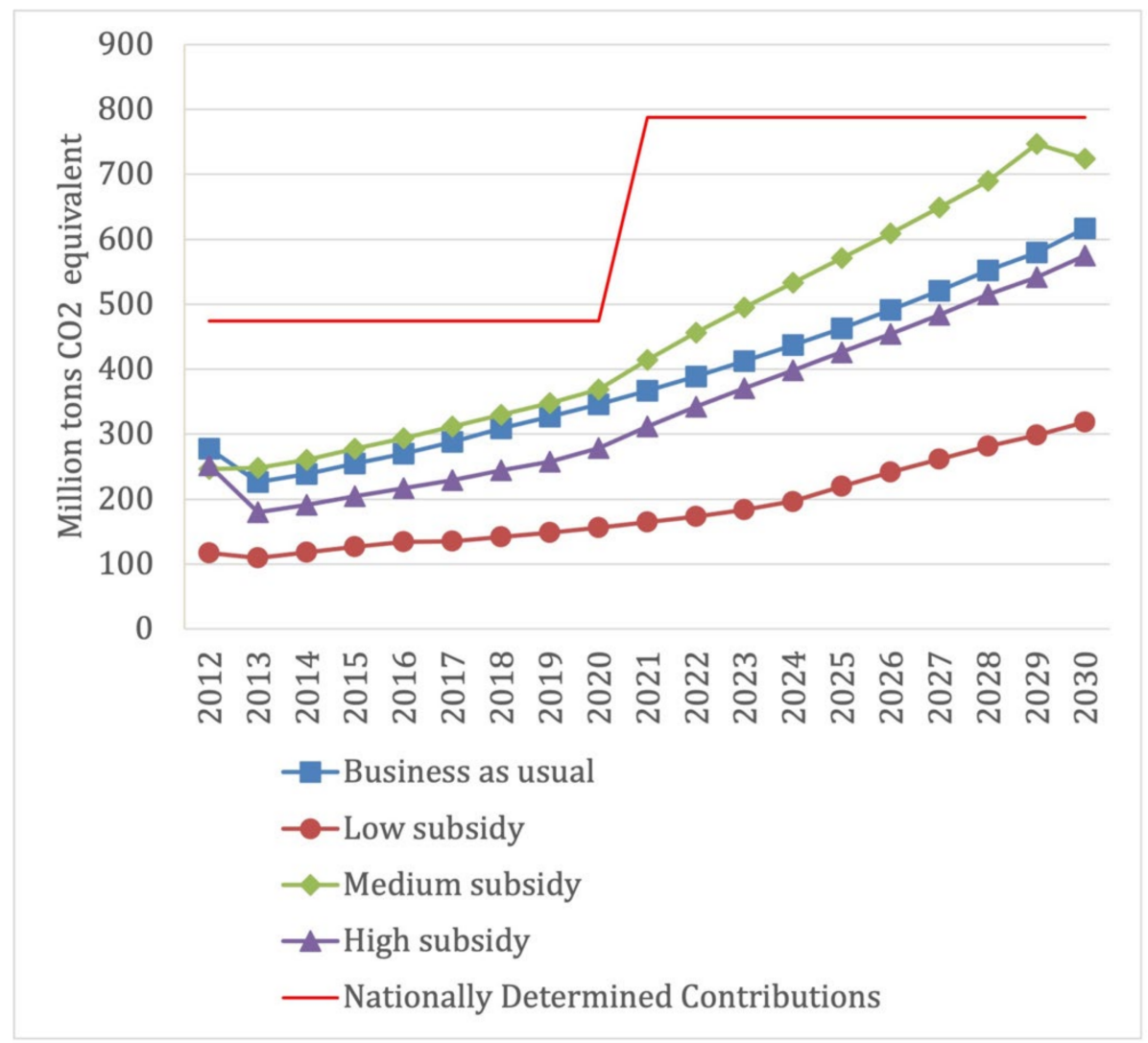

(a)

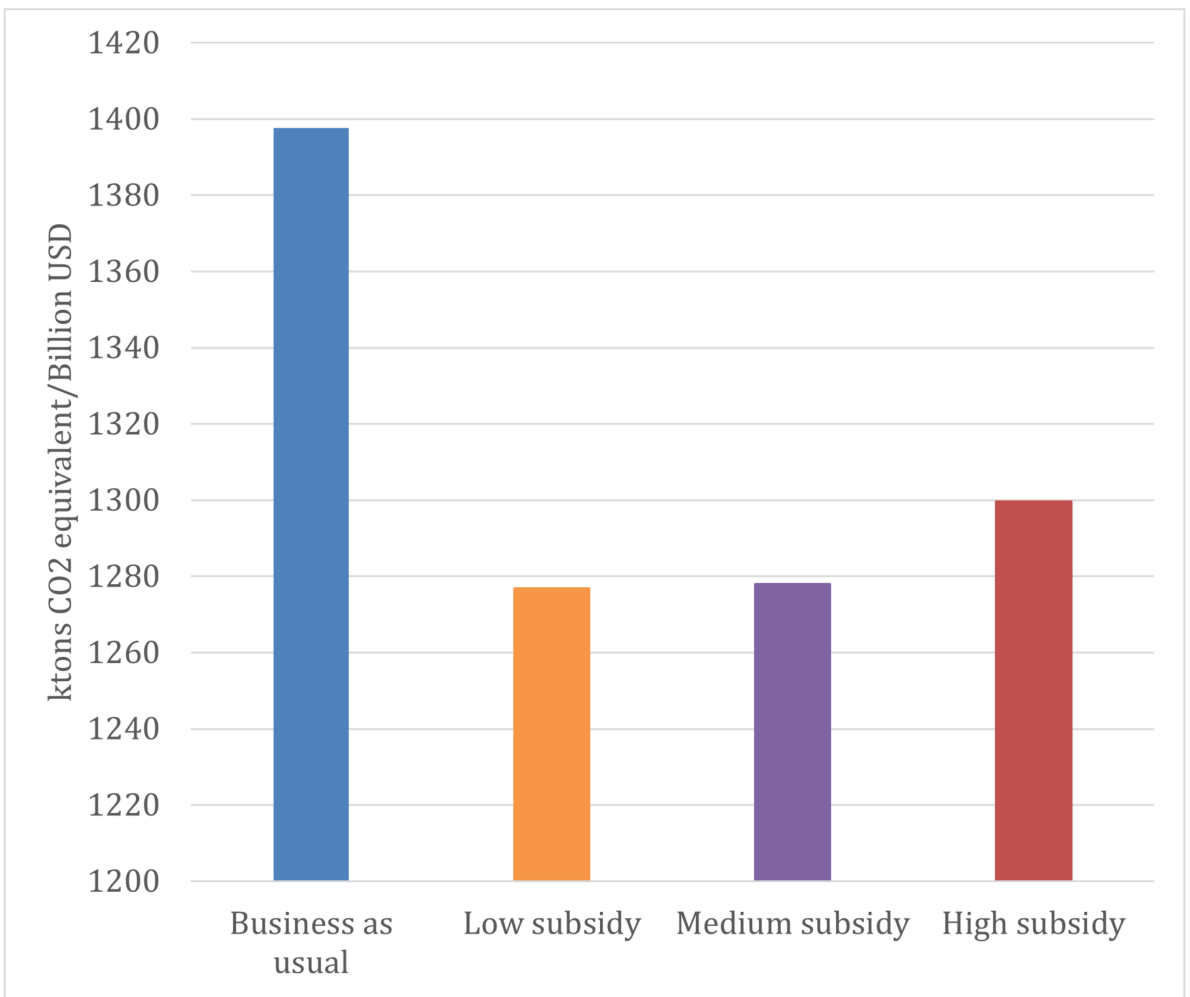

(b)

Figure 7. Greenhouse gas emission trends and intensity in different scenarios. (a) Total GHG emissions in different scenarios. (b) Average annual emission intensity in different scenarios. 


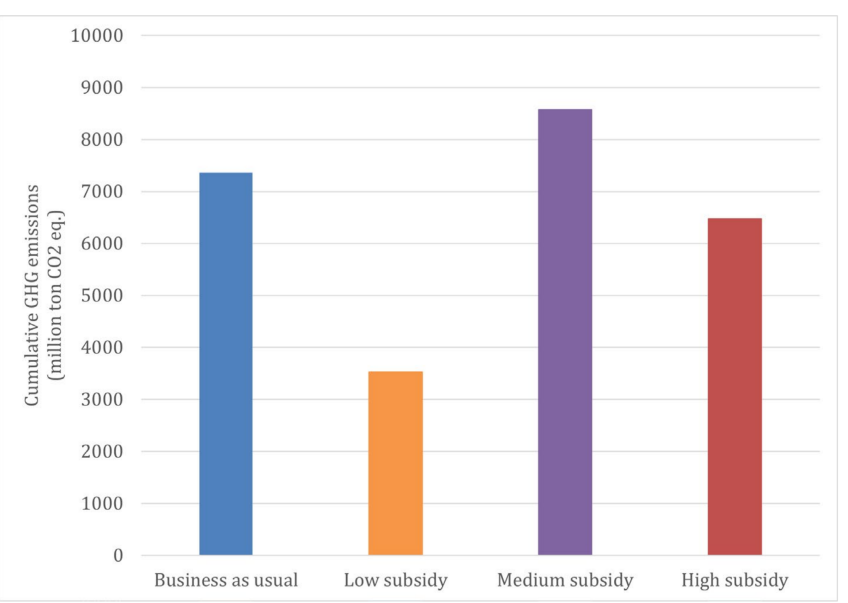

Figure 8. Cumulative GHG emissions in the period from 2012 to 2030 (million tons $\mathrm{CO}_{2}$ equivalent).

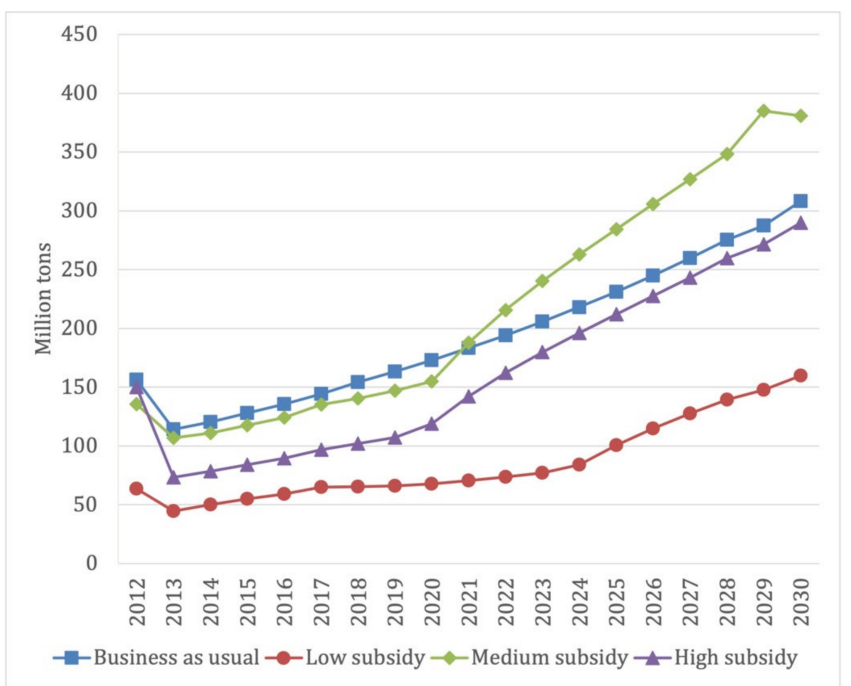

(a)

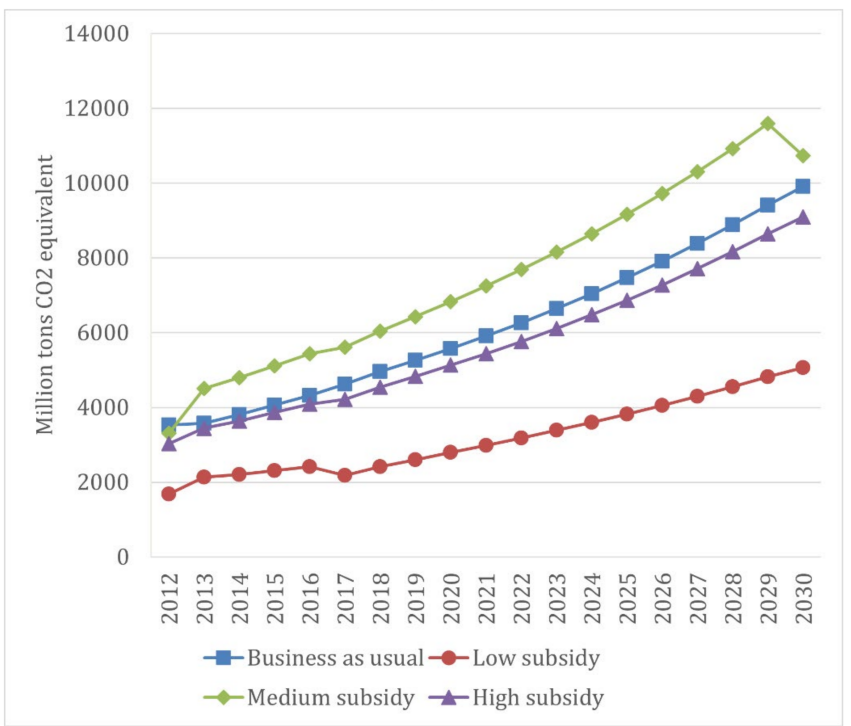

(b)

Figure 9. Cont. 


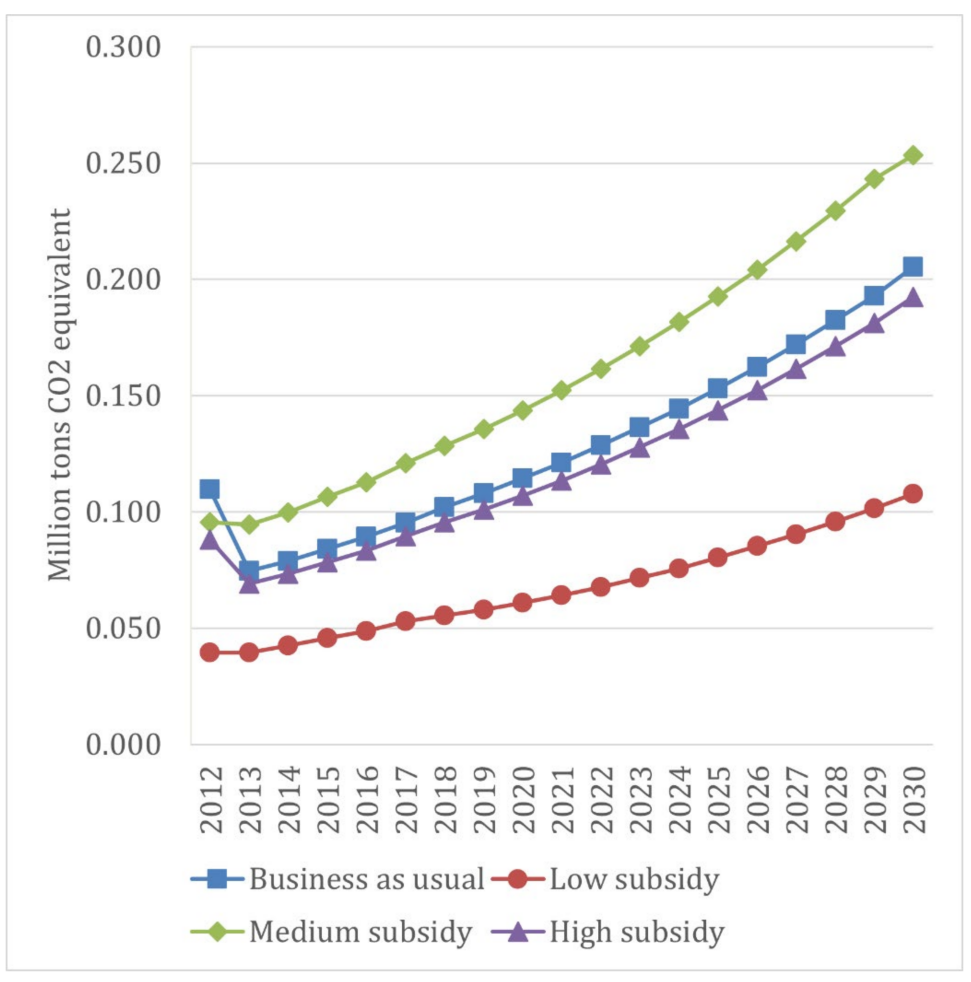

(c)

Figure 9. Comparison of air pollution mitigation in different scenarios. (a) Total $\mathrm{CO}_{2}$ emissions during the period from 2012 to 2030. (b) Total $\mathrm{CH}_{4}$ emissions during the period from 2012 to 2030. (c) Total $\mathrm{N}_{2} \mathrm{O}$ emissions during the period from 2012 to 2030.

However, GHG emissions cannot be the only factor to evaluate the carbon tax policy. The emissions should be combined with economic development evaluators, as Vietnam is an ambitious country with numerous development targets. Therefore, the effectiveness of mitigating GHG emissions should be combined with the consideration of economic development.

Finally, GHG emissions are significantly mitigated by the tax and subsidy mechanism's imposition and depend on policy implementation, as shown in different scenarios. For an emission reduction target, Case 1 is the scenario with the largest decrease in GHG intensity. However, optimal policymaking should consider both the effectiveness of GHG reduction and economic development.

\section{Conclusions}

As the ninth-most affected country by climate change in the last 20 years [1], Vietnam has recognized the need to commit to the climate change response. It has committed to reducing $8 \%$ of GHG emissions compared with the BAU scenario with domestic effort and up to $25 \%$ with international support. However, the dependence on international support makes Vietnam's mitigation efforts and internal advancement unsustainable in the long term. Therefore, this study proposes a self-sufficient tax and subsidy scheme to foster sustainable GHG reduction options through the assessment of economic impact and GHG reduction effectiveness.

This study proposes a simulation model to analyze economic and environmental data. The model is constructed with business-as-usual and low-, medium-, and high-subsidy scenarios demonstrating the different regulations to introduce alternative technical options. Each case is simulated according to three factors: GHG emissions, technology application, and economic development. The scenario design is based on a government development orientation and the ambition to introduce clean technology to mitigate GHG emissions in the energy sector. This study proposes implementing carbon tax and allocating subsidies 
to promote cleaner production in emission-intensive industries. The results are visualized as suggested policy options that will reduce air pollution and encourage economic development (see Figure 4). The results show that independent financial support for reducing GHG emissions is feasible for Vietnam, even alongside ambitious economic achievements. The model shows that the medium subsidy (up to $20 \%$ ) option will bring about the optimal scheme, with GHG emission reduction and economic development effectiveness.

In policymaking, the estimation of economic feasibility is a crucial step. Enabling any rigid policy instrument needs to consider possible impacts on the economy and environment. Therefore, the simulation model can contribute to a quantitative assessment of the economy, and it shows outstanding performance in the current context. Simultaneously, quantitative decision-making methods help make the investment appealing to stakeholders. Support the campaign to appeal to stakeholders for compliance. The evidence-based report provides informative communication compared to the ordinary ones, reinforcing higher implementation efficiency among stakeholders.

Vietnam is restructuring public finance, especially revenue sources, toward sustainable growth and development [51]. Accordingly, expanding the tax collection base instead of increasing taxes is one of the key measures recommended by specialized experts [10]. Therefore, carbon tax collection supports the expansion of tax collection facilities and strongly impacts environmental protection standards and manufacturing enterprises' awareness.

Currently, Vietnam has implemented environmental protection tax collection, no carbon tax. However, the effectiveness of this tax on the protection and handling of environmental issues is highly potential. If a series of environmental disasters were to occur, the authorities will respond slowly. The drawback is not only extending the time for disclosure, transparency of information, but also providing false information about economic consequences and the possible impacts of environmental disasters or concealing the compensation and environmental treatment from this tax revenue.

One of the weaknesses in public finance management in Vietnam is the transparency and efficiency in tax collection and spending is low. Public disclosure, transparency, and low accountability can infringe on the rights of the people, especially those who are taxed. Since then, the environmental tax not only does not create a sound effect for environmental protection, but it also raises conflicts, even creating inhibitory expressions in public opinion.

Therefore, with new taxes, such as carbon tax, before expanding the tax base, it is necessary to improve transparency and publicity on accountability and the tax base. Other processes, such as methods of tax collection, tax collection, and audit of expenditure sources, allocation to the beneficiaries of this tax source, and collective monitoring institutions must also be explicitly determined following the law.

Regarding the introduction of an economic instrument such as tax, the Vietnam government needs to consider the inventory system carefully. The most radical challenge is the underestimation or overestimation of GHG emissions. At the moment, the national GHG inventory is constructed by the 2006 IPCC Guidelines with the default emission factor for Tier 1, which is the primary method with less accurate data compared with Tier 2 and 3.

The second obstacle of introducing tax is the inventory of the synchronous categories between the economic inventory and environmental inventory. As mentioned above, the national GHG inventory is conducted with five main sectors by the 2006 IPCC Guidelines, which is different compared with commodities categories in the input-output table. On the other hand, all economic inventory is handled by the Ministry of Planning and Investment. The incorporation between the Ministry of Natural resources and Environment and the Ministry of Planning and Investment may lead to the disunion of sector categories. Nevertheless, the input-output table and investment matrix are both generated by the General Statistics Office, but there is still a discrepancy in the sector categories. This inconsistency of sector categories confuses the data preparation for the simulation analysis.

Nevertheless, some limitations of this study are worth noting. First, the simulated scenarios may overestimate Vietnam's ambition to develop renewable energy, as there are legal barriers to the introduction of an alternative technology framework. Revenues 
from taxes, fees, charges, and other payments must be transferred to the state budget balance without association with any obligatory expenditure [52]. Therefore, the allocation of subsidies may strain the state budget balance. Hence, future research can expand the analysis for a different consolidation of tax scheme and other subsidy forms. Further tax and subsidy combinations can create better alignment of the proposed policy options with existing regulation.

Second, some bias and confusion may have influenced the model estimates; the NDC of Vietnam seems to overestimate GHG emissions and economic development in the projection for 2030. The world has witnessed a tremendous crisis, COVID-19, which has systematically affected global economies [53]. In the next decade, socioeconomic development strategies in each nation must innovate to build resilience to such global economic shocks. Thus, future studies can focus on the situation, given this new orientation of socioeconomic development.

On the other hand, in recent years, the promotion of renewable energy in Vietnam has led to new problems of governance. Despite the explosion of solar energy production, renewable electricity still cannot be delivered to the consumer appropriately because of the limitation of grid-connection [54]. The existing electricity grid cannot endure the new massive loading capacity. The formidable barrier will involve a lengthy negotiation regarding the responsibility of upgrading the electricity grid between stakeholders. As this study did not account for the additional cost for the upgrade of electricity grids, this cost should be considered in future analysis.

Author Contributions: Conceptualization, A.Q.T.; supervision, T.M.; formal analysis, A.Q.T.; model building, A.Q.T. and T.M.; writing—original, A.Q.T.; writing—review and editing, A.Q.T. and T.M. All authors have read and agreed to the published version of the manuscript.

Funding: This work was funded in part by The Project for Human Resource Development Scholarship by Japanese Grant Aid (JDS).

Institutional Review Board Statement: Not applicable.

Informed Consent Statement: Not applicable.

Data Availability Statement: The IO table referred to is Vietnam's IO table in 2012 sourced from the General Statistics Office of Vietnam. The GHG emissions and data of mitigation options are compiled from Vietnam's Ministry of Natural Resources and Environment.

Acknowledgments: Authors acknowledge the General Statistics Office of Vietnam and Vietnam's Ministry of Natural resources and Environment for the data which is materials to the preparation of this manuscript.

Conflicts of Interest: The authors declare no conflict of interest.

\section{References}

1. Eckstein, D.; Hutfils, M.-L.; Winges, M. Global Climate Risk Index 2019. 2018. Available online: https:/ /germanwatch.org/sites/ default/files/Global\%20Climate\%20Risk\%20Index\%202019_2.pdf (accessed on 15 April 2021).

2. Vietnam Institute for Meteorology Hydrology and Climate Change and United Nations Development Programme. Viet Nam Special Report on Managing the Risks of Extreme Events and Disasters to Advance Climate Change Adaptation; Vietnam Institute for Meteorology Hydrology and Climate Change and United Nations Development Programme: Hanoi, Vietnam, 2015 ; pp. 1-253.

3. The Socialist Republic of Viet Nam. The Third National Communication of Viet Nam to the United Nations Framework Convention on Climate Change; The Socialist Republic of Viet Nam: Hanoi, Vietnam, 2018; pp. 1-108.

4. Darko, E.; Nguyen, H.M.; Whitley, S. Mapping Current Incentives and Investment in Viet Nam's Transport Sector: Informing Private Climate Finance; Overseas Development Institute: London, UK, 2015.

5. United Nations Development Programme. About Viet Nam. UNDP in Viet Nam. 2020. Available online: https://www.vn.undp. org/content/vietnam/en/home/countryinfo.html (accessed on 10 June 2020).

6. World Bank; OECD. GNI per Capita, Atlas Method (Current US\$) - Vietnam, Lower Middle Income. World Bank Open Data. 2020. Available online: https: / / data.worldbank.org/indicator /NY.GNP.PCAP.CD?end=2016\&locations=VN-XN\&start=2016 \&view=bar (accessed on 10 June 2020).

7. Government of Vietnam. Nationally Determined Contribution of Viet Nam. 2015. Available online: http:/ /www4.unfccc.int/ submissions/INDC/Published_Documents/Viet_Nam/1/VIETNAM $\backslash$ T1 $\backslash$ textquoterightS_INDC.pdf (accessed on 10 June 2020). 
8. United Nations. Paris Agreement. 2015. Available online: https://unfccc.int/sites/default/files/english_paris_agreement.pdf (accessed on 16 October 2021).

9. Nong, D.; Siriwardana, M.; Perera, S.; Nguyen, D.B. Growth of low emission-intensive energy production and energy impacts in Vietnam under the new regulation. J. Clean. Prod. 2019, 225, 90-103. [CrossRef]

10. World Bank; Government of Vietnam. Vietnam Public Expenditure Review: Fiscal Policies towards Sustainability, Efficiency, and Equity; World Bank: Washington, DC, USA, 2017.

11. The Socialist Republic of Viet Nam. Decision No. 432/QD-TTg Approval of Sustainable Development Strategy of Vietnam Period 2011-2020; The Socialist Republic of Viet Nam: Hanoi, Vietnam, 2012.

12. Fekete, H.; Kuramochi, T.; Roelfsema, M.; Elzen, M.D.; Forsell, N.; Höhne, N.; Luna, L.; Hans, F.; Sterl, S.; Olivier, J.; et al. A review of successful climate change mitigation policies in major emitting economies and the potential of global replication. Renew. Sustain. Energy Rev. 2021, 137, 110602. [CrossRef]

13. OECD. Climate Change Mitigation: Policies and Progress; OECD Publishing: Paris, France, 2015. [CrossRef]

14. Ministry of Natural Resources and Environment. Technical Report Vietnam's Intended Nationally Determined Contribution. Ministry of Natural Resources and Environment: Hanoi, Vietnam, 2015.

15. Tariq, A.; de Neergaard, A.; Jensen, L.S.; Sander, B.O.; Van Trinh, M.; Vu, Q.D.; Wassmann, R.; de Tourdonnet, S. Co-design and assessment of mitigation practices in rice production systems: A case study in northern Vietnam. Agric. Syst. 2018, 167, 72-82. [CrossRef]

16. Tariq, A.; Vu, Q.D.; Jensen, L.S.; de Tourdonnet, S.; Sander, B.O.; Wassmann, R.; Van Mai, T.; de Neergaard, A. Mitigating $\mathrm{CH}_{4}$ and $\mathrm{N}_{2} \mathrm{O}$ emissions from intensive rice production systems in northern Vietnam: Efficiency of drainage patterns in combination with rice residue incorporation. Agric. Ecosyst. Environ. 2017, 249, 101-111. [CrossRef]

17. Uddin, M.Z.; Mizunoya, T. An economic analysis of the proposed Dhaka-Chittagong Expressway in Bangladesh with the viewpoint of GHG emission reduction. Asia-Pacific J. Reg. Sci. 2020, 4, 285-314. [CrossRef]

18. Hoang, M.H.; Do, T.H.; Pham, M.T.; van Noordwijk, M.; Minang, P.A. Benefit distribution across scales to reduce emissions from deforestation and forest degradation (REDD+) in Vietnam. Land Use Policy 2013, 31, 48-60. [CrossRef]

19. Kamruzzaman, M.H.; Mizunoya, T. Quantitative analysis of optimum corrective fuel tax for road vehicles in Bangladesh: Achieving the greenhouse gas reduction goal. Asia-Pacific J. Reg. Sci. 2020, 5, 91-124. [CrossRef]

20. Jaccard, M.; Murphy, R.; Rivers, N. Energy-environment policy modeling of endogenous technological change with personal vehicles: Combining top-down and bottom-up methods. Ecol. Econ. 2004, 51, 31-46. [CrossRef]

21. Asian Development Bank. Assessment of Power Sector Reforms in Viet Nam: Country Report; Asian Development Bank: Manila, Philippines, 2015.

22. Vietnam Electricity. Annual Report 2018; Vietnam Electricity: Hanoi, Vietnam, 2018.

23. Schipper, L.; Le, T.A.; Orn, H.; Cordeiro, M.; Ng, W.-S.; Liska, R. Measuring the Invisible: Quantifying Emissions Reductions. 2008. Available online: http://pdf.wri.org/measuringtheinvisible_hanoi-508c_eng.pdf (accessed on 16 October 2021).

24. Ministry of Natural Resources and Environment; Ministry of Transport; Deutsche Gesellschaft für Internationale Zusammenarbeit GmbH (GIZ). NAMA Support Project Low Carbon Bus Document; GIZ: Hanoi, Vietnam, 2016.

25. Economic Research Institute for ASEAN and East Asia. Addressing Energy Efficiency in the Transport Sector through Traffic Improvement. 2017. Available online: https://www.eria.org/RPR_FY2016_04.pdf (accessed on 15 April 2021).

26. Fuhs, A.E. Hybrid Vehicles and the Future of Personal Transportation; CRC Press: Boca Raton, FL, USA, 2009. [CrossRef]

27. Raihan, S. Assessing the Implications from Trade Liberalisation: Use of Different Methods and Their Limitations; CUTS International: Jaipur, India, 2014.

28. Koks, E.E.; Carrera, L.; Jonkeren, O.; Aerts, J.C.J.H.; Husby, T.G.; Thissen, M.; Standardi, G.; Mysiak, J. Regional disaster impact analysis: Comparing input-output and computable general equilibrium models. Nat. Hazards Earth Syst. Sci. Discuss. 2016, 16, 1911-1924. [CrossRef]

29. Rose, A. Input-output economics and computable general equilibrium models. Struct. Chang. Econ. Dyn. 1995, 6, 295-304. [CrossRef]

30. Carter, A.P.; Petri, P.A. Leontief's contribution to economics. J. Policy Model. 1989, 11, 7-30. [CrossRef]

31. Leontief, W. Input-Output Economics; Oxford University Press: Oxford, UK, 1986.

32. Miller, R.E.; Blair, P.D. Input-Output Analysis: Foundations and Extensions, 2nd ed.; Cambridge University Press: Cambridge, UK, 2009.

33. Mahajan, S.; Beutel, J.; Guerrero, S.; Inomata, S.; Larsen, S.; Moyer, B.; Remond-Tiedrez, I.; Rueda-Cantuche, J.M.; Simpson, L.H.; Thage, B.; et al. Handbook on Supply, Use and Input-Output Tables with Extensions and Applications; European Commission: Geneva, Switzerland, 2018.

34. Wang, K.; Wang, J.; Wei, Y.M.; Zhang, C. A novel dataset of emission abatement sector extended input-output table for environmental policy analysis. Appl. Energy 2018, 231, 1259-1267. [CrossRef]

35. General Statistics Office of Viet Nam. Input-Output Table of Viet Nam in 2012; GSO: Hanoi, Vietnam, 2015.

36. Danish Energy Agency; Ministry of Industry and Trade; European Climate Foundation; Embassy of Denmark in Hanoi. Viet Nam Technology Catalogue. 2019. Available online: https://www.ea-energianalyse.dk/wp-content/uploads/2021/03/vietnam_ technology_catalogue_english.pdf (accessed on 28 October 2020).

37. e-Stat. Input-Output Table 2011. 2015. Available online: https:/ /www.e-stat.go.jp/stat-search / files?page=1\&layout=datalist\& toukei $=00200603 \&$ tstat $=000001073129 \&$ cycle $=0$ (accessed on 29 June 2020). 
38. Moriizumi, Y.; Hondo, H.; Nakano, S. Development and Application of Renewable Energy-Focused Input-Output Table. J. Jpn. Inst. Energy 2015, 94, 1397-1413. [CrossRef]

39. Journal of Finance-Ministry of Finance of Viet Nam. The State Bank of Viet Nam adjusts the interest rate (Vietnamese). 2020. Available online: http:/ / tapchitaichinh.vn/ngan-hang/ngan-hang-nha-nuoc-viet-nam-dieu-chinh-lai-giam-lai-suat-320202 .html (accessed on 30 June 2020).

40. Do, T.N.; Burke, P.J.; Baldwin, K.G.H.; Nguyen, C.T. Underlying drivers and barriers for solar photovoltaics diffusion: The case of Vietnam. Energy Policy 2020, 144, 111561. [CrossRef]

41. World Bank. State and Trends of CARBON Pricing 2016; World Bank: Washington, DC, USA, 2016.

42. The National Assembly of Viet Nam. Law No. 04/2017/QH14 on Provision of Assistance for Small and Medium-Sized Enterprises; The National Assembly of Viet Nam: Hanoi, Vietnam, 2017.

43. The Standing Committee of the National Assembly of Viet Nam. Resolution No. 579/2018/UBTVQH14 on Environmental Taxes; The Standing Committee of the National Assembly of Viet Nam: Hanoi, Vietnam, 2018.

44. Hong, B.D.; Slatick, E.R. Carbon Dioxide Emission Factors for Coal; Energy Information Administration: Washington, DC, USA, 1994; pp. 1-8. Available online: https://www.eia.gov/coal/production/quarterly/co2_article/co2.html (accessed on 18 November 2021).

45. US EPA. Greenhouse Gases Equivalencies Calculator-Calculations and References. 2021. Available online: https://www.epa. gov/energy/greenhouse-gases-equivalencies-calculator-calculations-and-references (accessed on 19 November 2021).

46. Willenbockel, D.; Hoa, H.C. Fossil Fuel Prices and Taxes: Effects on Economic Development and Income Distribution in Viet Nam; UNDP: New York, NY, USA, 2011.

47. Metzler, L.A. Taxes and subsidies in Leontief's Input-Output Model. Q. J. Econ. 1951, 65, 433-438. [CrossRef]

48. The Socialist Republic of Viet Nam. Decision No. 2068/QD-TTg Approving the Development Strategy of Renewable Energy of Viet Nam by 2030 with a Vision to 2050; The Socialist Republic of Viet Nam: Hanoi, Vietnam, 2015.

49. European Environment Agency. Manual for the EEA Greenhouse Gas Data Viewer. 2016. Available online: https: / / www.eea.europa.eu/data-and-maps/data/national-emissions-reported-to-the-unfccc-and-to-the-eu-greenhouse-gasmonitoring-mechanism-11/eea-greenhouse-gas-data-viewer-manual (accessed on 28 October 2020).

50. Ritchie, H.; Roser, M. $\mathrm{CO}_{2}$ and Greenhouse Gas Emissions-Our World in Data, OurWorldInData.org. 2017. Available online: https: / / ourworldindata.org/co2-and-other-greenhouse-gas-emissions\#citation (accessed on 27 June 2020).

51. Loi, N.V. Restructuring the State Budget towards Fiscal Sustainability in Vietnam, National Institute for Finance; National Institute for Finance: Hanoi, Vietnam, 2018.

52. The National Assembly. Law no. 83/2015/QH13 on State Budget. 2015. Available online: http://vanban.chinhphu.vn/portal/page/ portal/chinhphu/hethongvanban?class_id=1\&_page=1\&mode=detail\&document_id=180627 (accessed on 28 October 2020).

53. Tisdell, C.A. Economic, social and political issues raised by the COVID-19 pandemic. Econ. Anal. Policy 2020, 68, 17-28. [CrossRef]

54. Hieu, C. The Concern of Wind Energy with "Anguishing Lesson" from the Solar Energy (In Vietnamese), Electronic Newspaper of Thanh Nien. 2020. Available online: https:// thanhnien.vn/tai-chinh-kinh-doanh/dien-gio-lo-bai-hoc-dau-xot-cua-dien-mattroi-tai-dien-1174852.html (accessed on 10 June 2020). 